\title{
Ascending Colon Duplication- A Case Report with Review of Literature
}

\author{
By Guru Prasad Painuly, Col. Ashok Tyagi, Rashk Kaushal \& Mini Singhal
}

Max Super Specialty Hospital

Abstract- Gastro - intestinal duplications are usually detected in children before 2 years of age due symptoms/complications associated with the condition or during surgery in the child for some unrelated condition. In adults colonic duplication is of rare occurrence and often diagnosed during surgery. However, it may be diagnosed pre operatively due to symptoms of obstruction, volvulus or rarely due to perforation. We present an adult having tubular duplication of ascending colon, that presented with perforation. The duplication had a blind end and did not have distal communication. In addition, it had its own blood supply. The management of the case is discussed. Aetiogenesis of the anomaly is enumerated and literature reviewed.

For ascending colon duplication similar meaning word accessory ascending colon has also been used in the manuscript.

Keywords: gastro - intestinal tract duplication, colonic duplication, tubular duplication of colon.

GJMR-I Classification: NLMC Code: WI 520

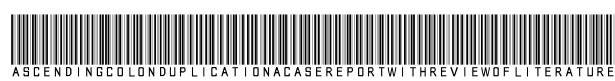

Strictly as per the compliance and regulations of:

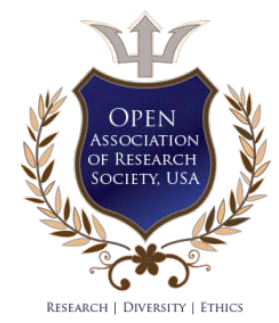

(C) 2021. Guru Prasad Painuly, Col. Ashok Tyagi, Rashk Kaushal \& Mini Singhal. This research/review article is distributed under the terms of the Attribution-NonCommercial-NoDerivatives 4.0 International (CC BY-NC-ND 4.0). You must give appropriate credit to authors and reference this article if parts of the article are reproduced in any manner. Applicable licensing terms are at https://creativecommons.org/licenses/by-nc-nd/4.0/. 


\title{
Ascending Colon Duplication- A Case Report with Review of Literature
}

\author{
Guru Prasad Painuly ${ }^{\alpha}$, Col. Ashok Tyagi $^{\sigma}$, Rashk Kaushal $^{\rho} \&$ Mini Singhal ${ }^{\omega}$
}

Abstract- Gastro - intestinal duplications are usually detected in children before 2 years of age due symptoms/complications associated with the condition or during surgery in the child for some unrelated condition. In adults colonic duplication is of rare occurrence and often diagnosed during surgery. However, it may be diagnosed pre operatively due to symptoms of obstruction, volvulus or rarely due to perforation. We present an adult having tubular duplication of ascending colon, that presented with perforation. The duplication had a blind end and did not have distal communication. In addition, it had its own blood supply. The management of the case is discussed. Aetiogenesis of the anomaly is enumerated and literature reviewed.

For ascending colon duplication similar meaning word accessory ascending colon has also been used in the manuscript.

Keywords: gastro - intestinal tract duplication, colonic duplication, tubular duplication of colon.

\section{INTRODUCTION}

G astro-intestinal duplications are uncommon anomaly. The incidence has been reported as 1 per 4500 births by the various authors ${ }^{1}$. Due to complications of acute abdomen or bowel obstruction, most cases (65-80\%) are detected in children by the age of 2 years ${ }^{2,3,4,5,6,7.8}$. This is the reason that most cases have been reported in children and a few number of cases have been reported in adults. Amongst gastro - intestinal duplication colonic duplication represents only $7-20 \%$ cases $^{2,3}$. Fotiadis et al stated that most of the time definitive diagnosis of colonic duplication is made during a laparotomy ${ }^{6}$.

The differential diagnosis includes enteric cyst, giant colonic diverticulum, volvulus colon, duplication cyst. If not diagnosed in childhood, then these anomalies may come to notice in the later life as a chance finding (being asymptomatic) during an unrelated surgery. When associated with symptoms of intestinal obstruction, volvulus or compression of normal

Corresponding Author a: Principal Surgical Consultant Department of General and Laparoscopic Surgery, Max Super Specialty Hospital Dehradun 248001 India. e-mail: gppainuly@gmail.com

Author $\sigma$ : Senior Surgical Consultant Department of General and Laparoscopic Surgery, Max Super Specialty Hospital Dehradun 248001 India.

Author p: Junior Resident Department of Surgery, Max Super Specialty Hospital Dehradun 248001 India.

Author w: Principal Consultant Department of Pathology and Laboratory Services, Max Super Specialty Hospital Dehradun 248001 India. adjacent bowel by the expanding blind end duplication ${ }^{6,9}$. It may also present with symptoms and signs of diverticulitis ${ }^{10}$. Rarely in case of presence of ectopic gastric mucosa with ulceration bleeding or perforation may occur ${ }^{9,10}$. The relative occurrence of digestive duplication has been reported as follows ${ }^{2,11}$. jejunum $8 \%$, lleal $30 \%$, ileocecal valve $30 \%$, colon $6-7 \%$, rectum $2-3 \%$. The complications of colonic duplication include development of adenocarcinoma, squamous carcinoma and carcinoid tumour ${ }^{12,13,14}$. Fora true digestive duplication, Rowling has set forth the following criteria $^{15}$

1. The wall of duplication should be in continuity with one of the duplicated organs.

2. The cyst is surrounded by a smooth muscle layer.

3. A layer of digestive mucosa is present (Typical or Heterotrophic).

Examples include gastric/colonic/pancreatic

\section{il. Case Report}

A 45 Year aged male was brought to ER as a case of acute abdomen. He had severe pain in abdomen, abdominal distension and h/o obstipation. He had signs of intestinal perforation. A bed side $U / S$ and Xray abdomen erect (in sitting position) revealed free air under dome of diaphragm and also shadow of colonic lump. The findings were suggestive of intestinal perforation. Patient did not consent for CT abdomen, and hence with a presumptive diagnosis of volvulus sigmoid colon with perforation emergency exploratory laparotomy was done. Exploration revealed a free $40 \mathrm{~cm}$ long segment of colon that originated proximal to hepatic flexure. The duplicated ascending colon had a blind end distally, that reached pelvic brim. It was grossly distended and there was a big perforation at its origin from the primary colon (Figure 1,2 and 3). The ascending colon was excised from proximal to origin of duplication along with right colonic flexure. Both colonic ends were closed and a side-to-side hand sewn anastomosis was done. A covering proximal loop ileostomy was formed for temporary diversion. Patient had postoperative sepsis and had a prolonged hospital stay of 21 days. 4 months later uneventful ileostomy closure was done. 


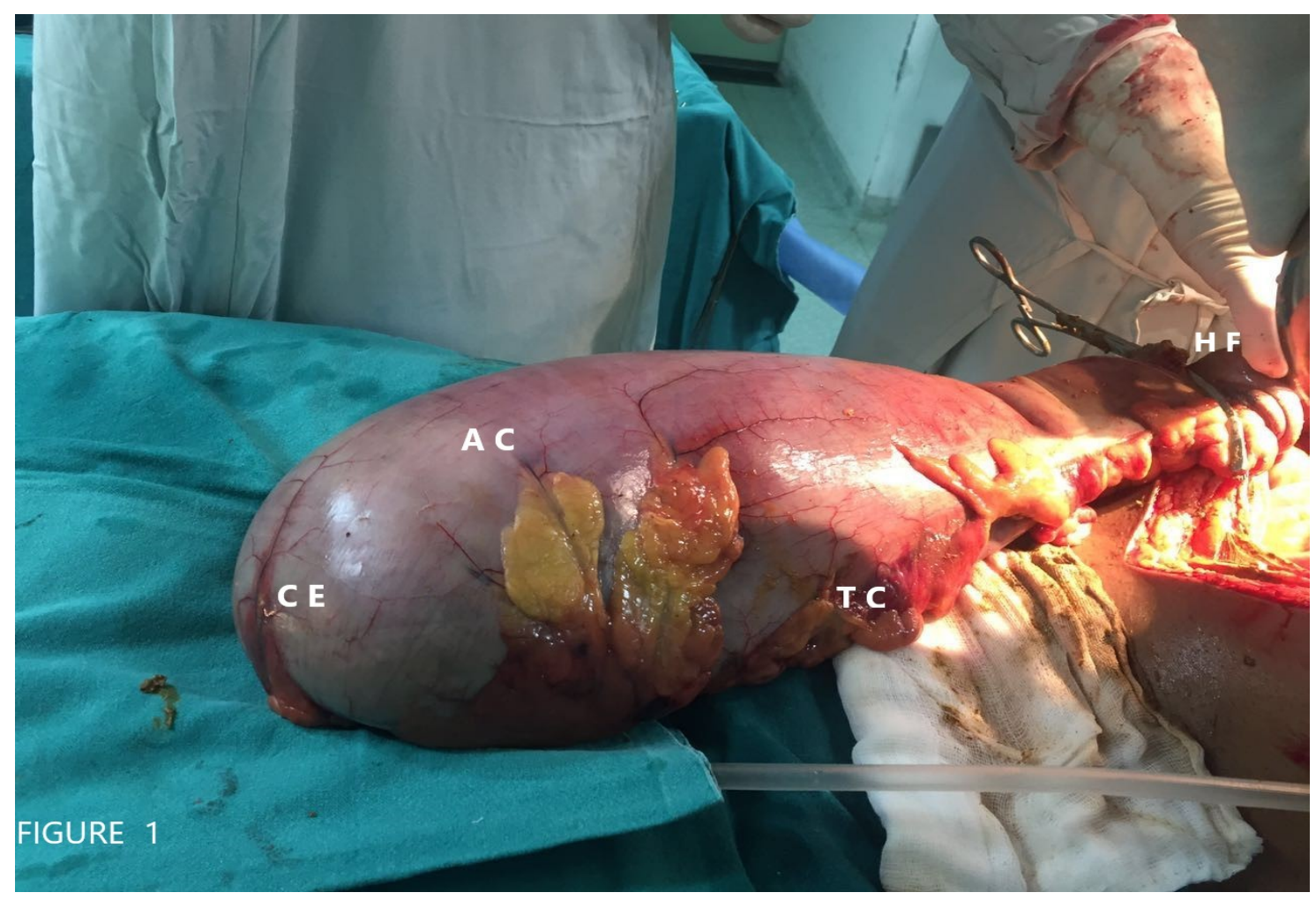

AC: Accessory ascending colon, TC: Taenia coli

Figure 1: Long duplication of ascending colon with distal free blind end.

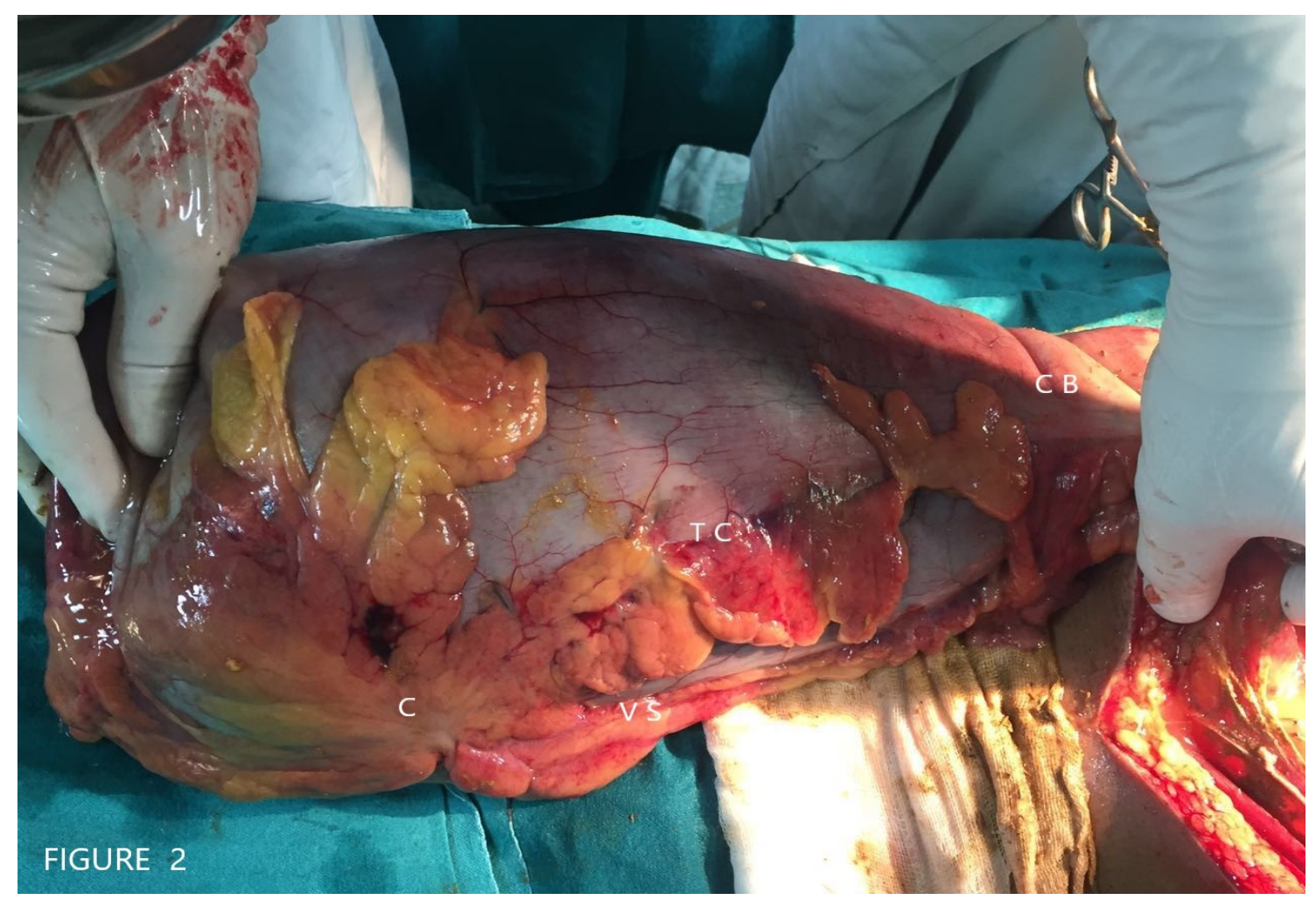

VS: Vascular supply, C: Confluence of taenia in accessory ascending colon

Figure 2: Separate arterial feeder of accessory ascending colon. 


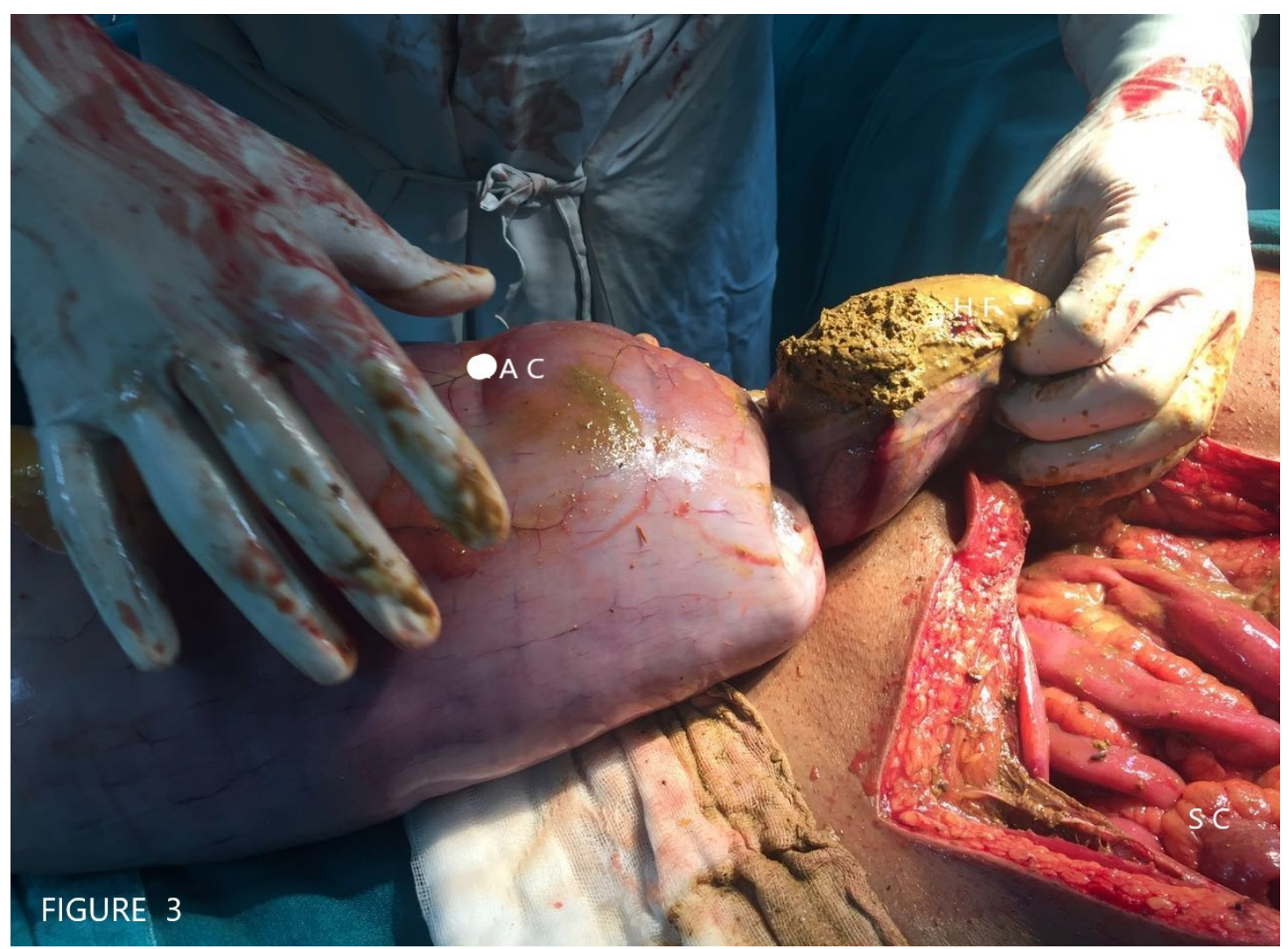

HF: Hepatic flexure, Transverse colon with colonic band is also visible.

Figure 3: Hepatic flexure with big proximal perforation at the junction of ascending and accessory ascending colon.

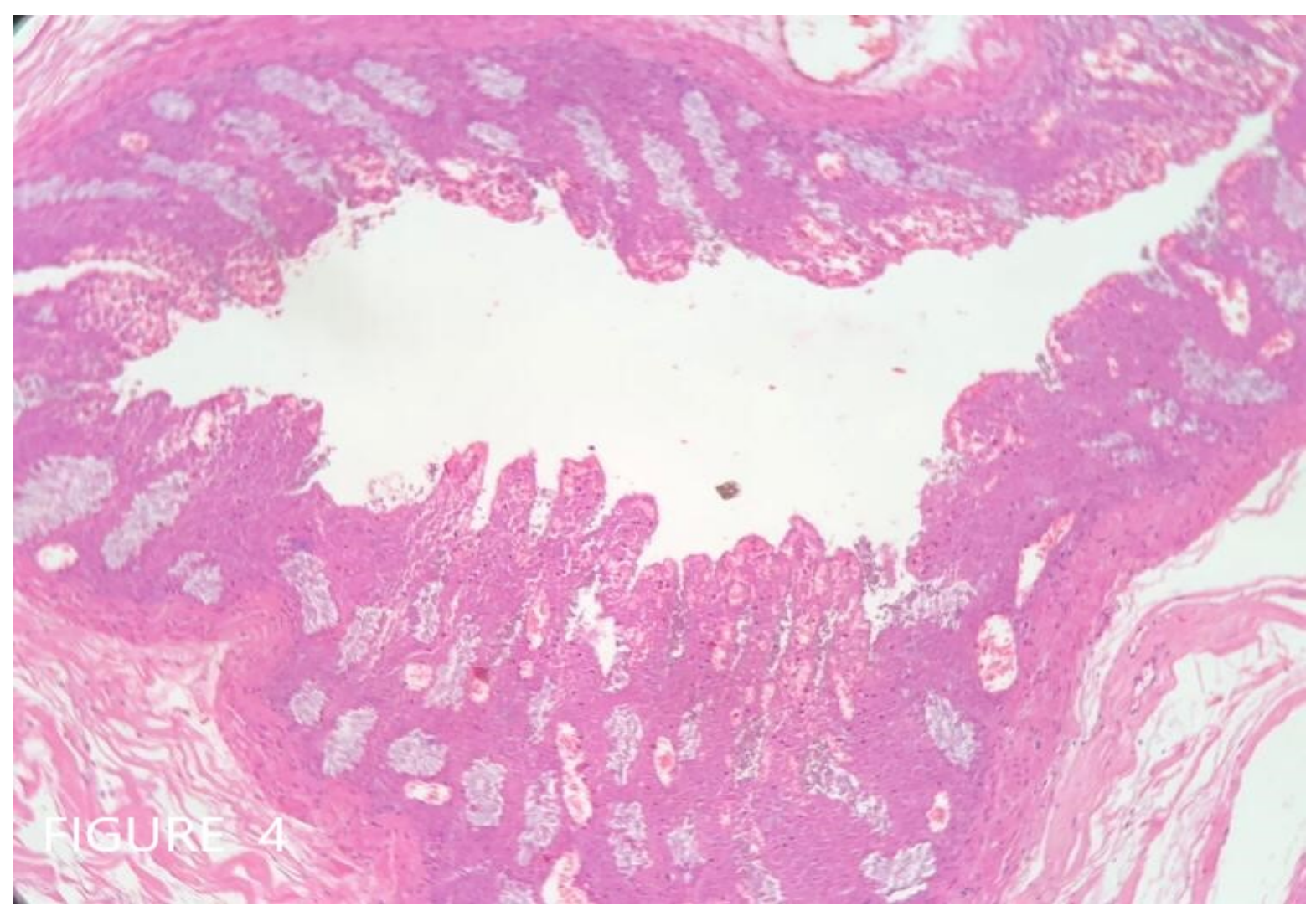

Figure 4: Histo-biopsy of the excised accessory ascending colon 


\section{ili. Diagnosis and Management}

Sonography, CT scan, Contrast enema and Colonoscopy have been suggested for the diagnosis ${ }^{16}$. Contrast CT is best modality in diagnosis, however preoperative diagnosis is difficult ${ }^{17}$. In addition, MRI and Contrast MRI have also been used in the diagnosis of colonic duplication.

Surgical resection of duplication with attached normal colonic segment to avert the risk of developing cancer in the duplicated colon is recommended ${ }^{2,3}$. Currently laparoscopic resection of colon duplication has been advocated ${ }^{18,19,20}$. Laparoscopic surgery is a preferred approach in the management of gastrointestinal duplications ${ }^{21}$. In huge barrel shaped colonic duplication selective mucosal excision with preservation of sero-muscular layer or distal internal drainage by excision of the common wall of duplication may be an effective alternative $e^{2,3,5,22}$.

\section{Aetiogenesis, Classification and ReView of Literature}

Historically first case of colonic duplication was reported in 1733 by $\mathrm{Cadler}^{23}$. Another case was described by Suppinger in 1876, and the term 'duplication of alimentary tract' was first coined by Ladd in 1937. The exact cause of colonic duplication remains unknown, however environmental factors like trauma and hypoxia etc. have been implicated in its formation ${ }^{24}$. Lewis et al proposed the diverticular theory, whereas alterations in closure of embryonic disc have been attributed as the cause of colonic duplication by others. Yet another theory regarding colonic duplication was proposed by Smith. It describes dorsal protrusion of yolk sac caused by its herniation or adherence to ectoderm responsible for the condition. This theory explains the Genito-urinary problems associated with duplication of hindgut. However, the most plausible theory having comprehensive explanation is given by Bremer. It states aberrant lumen recanalization of the gut in the embryo as the cause of colonic duplication. Since the duplication develops within the intestine, the outer wall contains all tissue layers and its counterparts ${ }^{25}$.

Colonic duplications are difficult to differentiate from Mc Nutt's type 3 or Choony and Frizell's type 2 giant diverticulum ${ }^{8,26}$. Gross et al described 4 varieties of duplication ${ }^{4}$ -

1. A tubular structure that branches out from intestine and extends for some distance between mesenteric leaves.

2. A double barrel structure communicating with the intestine lumen at one or both ends.

3. A cystic structure lying in the peritoneal cavity attached by a mesenteric stalk.
4. A spherical lesion contiguous with some part of the bowel particularly along the ileum.

Tubular Duplication can be barrel type or T/Y shaped.

McPherson classified colonic duplication into 3 groups $^{27}$

Type I Simple cyst

Type II Diverticulum

Type III Tubular colonic duplication

Stern at al reported that $80 \%$ colonic duplications are cystic type, and $20 \%$ cases are tubular ${ }^{5}$.

Another classification envisages length/extent of involvement of colon/bowel. 2 Types are described -

Type I is limited to colon or rectum and is usually partial. If these lesions project into the lumen of bowel, patient may have intussusception leading to obstruction ${ }^{5,28}$.

Type // duplications most of the time involve entire colon and are associated with genital or lower urinary tract anomalies. These may also be associated with intestinal mal rotation, duplication of ileum and appendix, spinal anomalies, omphalocele, exstrophy of urinary bladder and other abdominal wall anomalies. Double barrel duplication is usually associated with distal anomalies, terminal fistula or imperforated anus(type $\mathrm{Ilb}$ and $\mathrm{c}$ ). These duplications communicate with the bowel proximally, and in most cases do not have distal communication. Thus, these may become distended with faecal matter and cause obstruction of the adjacent bowe ${ }^{29,30}$. Patient may have pain due to over distension or inflammation. Due to ulceration of the aberrant mucosa present in the duplicated segment, gastrointestinal bleeding may occur ${ }^{4}$. Unless associated with another congenital anomaly, duplication having a distal communication are usually asymptomatic. Usually, duplication is present along the ante mesenteric border of bowel, whereas it is lateral in position in case of ascending colon. Transverse colon duplications occur along supra colic margin. Rectal duplications occur posterior to rectum and both have common mesentery and blood supply, however loop duplication have a separate mesentery and blood supply. Tubular duplications sometimes can have direct communication with perineum ${ }^{3,30}$. Tubular type of colonic duplication ( $T$ or $Y$ type) have only one communication with the native bowel and the other end forms a blind pouch (as in our present case). Sometimes the distal end may communicate distally forming perianal and Genitourinary fistula and imperforated anus ${ }^{20}$.

Due to number of cases being small, literature has mostly case reports rather than large series or multiinstitutional series. Rarely complete duplication of colon may occur ${ }^{29,30}$. Reporting cases from 1950 - 2005, Fotiadis $\mathrm{C}$ et al reported total 83 cases $^{6}$.

Roberts $\mathrm{M}$ et al reported 2 cases of sigmoid duplication that were pre operatively misdiagnosed as carcinoma ${ }^{7}$. Historically a case of colonic triplication has 
been reported by Gray, A.W. ${ }^{31}$ Lee $\mathrm{KH}$ et al reported laparoscopy for the first time in the management of intestinal duplication in a child ${ }^{32}$. A case of asymptomatic tubular duplication of transverse colon has been reported by Kim YW et al ${ }^{33}$. 2 Cases of colonic duplication that presented as rectal bleeding have also been reported by Fotiadis $C$ et $\mathrm{al}^{6}$. 7 case reports of colonic duplication in adults were also reported. Of these 4 patients presented as abdominal pain and 3 had intestinal obstruction ${ }^{34}$. A ' $Y$ ' shaped colonic duplication has been reported by Chang et $\mathrm{al}^{35}$. A. Sozutek et al reported a case of perforated caecal duplication cyst presenting as peritonitis ${ }^{36}$. An adult female had a sigmoid colon duplication, that was preoperatively diagnosed as colonic diverticula ${ }^{8}$. Jung $\mathrm{Hi}$ et al have reported a complete tubular duplication of colon in adult female with Colo-vaginal fistula ${ }^{37}$. Wu X et al also reported a case of tubular colonic duplication in an adult ${ }^{38}$. Another anomaly presenting with multi segmental asymptomatic duplication of colon has been reported ${ }^{39}$. Kung-Chuan Cheng et al reported a case of colonic duplication that presented as a huge abdominal mass in an adult female ${ }^{40}$. Yet another case of colonic duplication cyst in adult female has been reported by Shrestha $S$ and Adhikari $S^{41}$. Li GB et al managed a case of tubular colonic duplication and published it ${ }^{42}$. Recently Reddyn $V$ et al reported a case of intestinal duplication in an elderly male that presented as sigmoid volvulus ${ }^{43}$.

\section{Take Home Message}

Diagnosis of colonic duplication should be suspected in an adult with chronic colicy pain with constipation as the condition may get unrecognized till adulthood. Patient may also have abdominal lump, distension- usually chronic in nature. However rarely it can also present as acute emergency. The pre-operative diagnosis may be difficult without radiological investigations because of vague clinical and radiological presentation. Treatment is to admit the patient and do open or laparoscopic resection of duplication along with attached normal colonic segment.

\section{References Références Referencias}

1. Schalamon, Schleef J, Howarth ME. Experience with gastro-intestinal duplication in childhood. Langenbecks Arch Surg. 2000; 385:402-405. [Pub Med] [DOI]

2. Puligandla PS, Nguyen LT, St-Vil D, Flageole $H$, Bensoussan AL, Nguyen VH, Laberge JM. Gastrointestinal duplications. J Pediatr Surg. 2003; 38: 740-744. [PubMed] [DOI]

3. Holcomb GW, Gheissari A, O'Neill JA, Shorter NA, Bishop HC. Surgical management of alimentary tract duplications. Ann Surg. 1989; 209:167174. [PubMed] [DOI]
4. Gross RE, Holcomb GW, Farber S. Duplications of the alimentary tract. Pediatrics. 1952; 9:448468. [PubMed]

5. Stern LE, Warner BW. Gastrointestinal duplications. Semin Pediatr Surg. 2000; 9:135-140. [PubMed] [DOI]

6. Fotiadis C, Genetzakis M, Papandreou I, et al. Colonic duplication in adults: report of two cases presenting with rectal bleeding. World J Gastroenterol 2005;11:5072-4 [PMC free article] [PubMed] [Google Scholar]

7. Roberts $\mathrm{M}$, Rabinovitch J, Felton $\mathrm{CM}$, et al. Duplication of the sigmoid colon. Ann Surg 1959;150:904-8 [PMC free article] [PubMed] [Google Scholar]

8. Al-Jaroof AH, Al-Zayer F, Meshikhes AW. A case of sigmoid colon duplication in an adult woman. BMJ Case Rep. 2014 Aug 5; 2014: bcr2014203874. doi: 10.1136/bcr-2014-203874. PMID: 25096653; PMCID: PMC4127677.

9. Correia-Pinto J, Romero R, Carvalho JL, Silva G, Guimarães $H$, Estevão-Costa J. Neonatal perforation of a Y-shaped sigmoid duplication. J Pediatr Surg. 2001; 36:1422-1424. [PubMed] [Google Scholar]

10. Paulson EC, Mahmoud NN. Sigmoid colon duplication cysts. Am Surg 2008; 74: 250-2 [PubMed] [Google Scholar]

11. Kekez T, Augustin G, Hrstic I, Smud D, Majerovic M, Jelincic Z, Kinda E. Colonic duplication in an adult who presented with chronic constipation attributed to hypothyroidism. World J Gastroenterol. 2008; 14:644-646. [PMC free article] [PubMed] [Google Scholar]

12. Delladetsima J, Papachristodoulou A, Zografos G. Carcinoma arising in a duplicated colon. Am Surg. 1992; 58:782-783. [PubMed] [Google Scholar]

13. Letarte F, Sideris L, Leblanc G, Leclerc YE, Dube P. Pseudomyxoma peritonei arising from intestinal duplication. Am Surg. 2011; 77:233-234. [PubMed] [Google Scholar]

14. Hickey WF, Corson JM. Squamous cell carcinoma arising in a duplication of the colon: case report and literature review of squamous cell carcinoma of the colon and of malignancy complicating colonic duplication. Cancer. 1981; 47:602-609. [PubMed] [Google Scholar]

15. Rowling JT. Some observations on gastric cysts. $\mathrm{Br}$ J Surg. 1959; 46: 441-445. [PubMed] [Google Scholar]

16. Banchini F, Delfanti R, Begnini E, Tripodi MC, Capelli P. Duplication of the transverse colon in an adult: case report and review. World J Gastroenterol. 2013 Jan 28; 19(4): 586-9. doi: 10.3748/wjg. v19.i4.586. PMID: 23382641; PMCID: PMC3558586. 
17. Carneiro FP, de Nazareth Sobreira M, de Azevedo AE, Alves AP, Campos KM. Colonic duplication in an adult mimicking a tumour of pancreas. World $\mathrm{J}$ Gastroenterol. 2008; 14: 966-968. [PMC free article] [PubMed] [Google Scholar]

18. Park YA, Jung EJ, Han SJ. Laparoscopic resection of duplicated sigmoid colon under the guidance of intraoperative colonoscopy. Surg LaparoscEndosc Percutan Tech 2005;15:299-301 [PubMed] [Google Scholar]

19. Kiu V, Liang JT. Laparoscopic resection of Y-shaped tubular duplication of the sigmoid colon: report of a case. Dis Colon Rectum 2010; 53: 949-52 [PubMed] [Google Scholar]

20. Yong $\mathrm{YG}$, Jung $\mathrm{KU}$, Cho $\mathrm{YB}$, et al. Large tubular colonic duplication in an adult treated with a small midline incision. J Korean Surg Soc 2012; 82: 1904 [PMC free article] [PubMed] [Google Scholar]

21. Kyo K, Azuma M, Okamoto K, Nishiyama M, Shimamura T, Maema A, Shirakawa M, Nakamura T, Koda K, Yokoyama H. Laparoscopic resection of adult colon duplication causing intussusception. World J Gastroenterol. 2016 Feb 21; 22(7): 2398402. doi: 10.3748/wjg.v22.i7.2398. PMID: 26900303; PMCID: PMC4735015.

22. Ildstad ST, Tollerud DJ, Weiss RG, Ryan DP, McGowan MA, Martin LW. Duplications of the alimentary tract. Clinical characteristics, preferred treatment, and associated malformations. Ann Surg. 1988; 208:184-189. [PubMed] [DOI]

23. K Kume, H Sakata, M Otsuki Gastrointestinal: Tubular duplication of the descending colon. First published: 15 August 2007 https://doi.org/10.1111/ j.1440-1746.2007.05134.x

24. Bishop HC, Koop CE. Surgical management of duplications of the alimentary tract. Am J Surg. 1964; 107: 434-442. [PubMed] [Google Scholar]

25. Bremer JL. Diverticula and duplications of the intestinal tract. Arch Pathol. 1944; 38:132140. [Google Scholar]

26. McNutt R, Schmitt D, Schulte W. Giant colonic diverticula-three distinct entities. Report of a case. Dis Colon Rectum 1988; 31: 624-8 [PubMed] [Google Scholar]

27. McPherson AG, Trapnell JE, Airth GR. Duplication of the colon. Br J Surg. 1969; 56: 138-142. [PubMed] [Google Scholar]

28. Ohno T, Shiogama T, Mochizuki S, Mizutani A, Tsurunaga $\mathrm{Y}$, Fukui $\mathrm{H}$, Aso N. Huge cystic communicating duplication of the right colon with perforated appendicitis. Surgery. 2005; 137: 477479. [PubMed] [DOI]

29. Frittelli P, Costa G, Zanella L, Sguazzini G, Rossi FS. Intestinal duplication in the adult. A case report of colonic duplication and a review of the literature. Chir Ital. 2002; 54: 721-728. [PubMed] [Google Scholar]
30. Li L, Zhang J, Wang Y, Chen R, Qin H. Complete duplication of the colon: definitive management by resection of the duplication without the normal bowel. Chin Med J (Engl) 2002; 115: 779781. [PubMed] [Google Scholar

31. GRAY, A. W. Triplication of large intestine. Arch. Path., I 940, 30, 121 5- 1222

32. Lee $\mathrm{KH}$, Tam YH, Yeung CK. Laparoscopy in the management of intestinal duplication in childhood. Aust N Z J Surg. 2000 Jul; 70(7): 542-4. doi: 10. 1046/j.1440-1622.2000.01891. x. PMID: 10901587.

33. Kim YW, Kim J, Lee KY, Kim NK, Cho CH. Asymptomatic tubular duplication of the transverse colon in an adult. Yonsei Med J. 2005 Feb 28; 46(1): 189-91. doi: 10.3349/ymj.2005.46.1.189. PMID: 15744828; PMCID: PMC2823051.

34. Mourra N, Chafai N, Bessoud B, Reveri V, Werbrouck A, Tiret E. Colorectal duplication in adults: report of seven cases and review of the literature. J Clin Pathol. 2010 Dec; 63(12):1080-3. doi: 10.1136/jcp.2010.083238. Epub 2010 Oct 5. PMID: 20924093.

35. Chang, Hao-Cheng \& Huang, Shih Chiang \& Chen, Tse-Ching \& Lai, Ming-Wei \& Chen, Shih \& Lai, JinYao. (2011). Y-shaped colonic duplication: report of a case and literature review. Chang Gung medical journal. 34. 43-7.

36. A. Sozutek, T. Colak, A. Dag, O. Karak Cecal duplication cyst presenting as perforation in an adult patient Turk J Gastroenterol, 23 (2012), pp. 818-819 CrossRefView Record in ScopusGoogle Scholar

37. Jung HI, Lee HU, Ahn TS, Lee JE, Lee HY, Mun ST, Baek MJ, Bae SH. Complete tubular duplication of colon in an adult: a rare cause of colovaginal fistula. Ann Surg Treat Res. 2016 Oct; 91(4):207-211. doi: 10.4174/astr.2016.91.4.207. Epub 2016 Sep 30. PMID: 27757399; PMCID: PMC5064232.

38. Wu X, Xu X, Zheng C, Li B. Tubular colonic duplication in an adult: case report and brief literature review. J Int Med Res. 2018 Jul; 46(7): 2970-2975. doi: 10.1177/0300060518773016. Epub 2018 May 15. PMID: 29761727; PMCID: PMC6124274

39. Valizadeh, Neda MD1; Guddati, Harish MD1; Boroda, Konstantin MD2; Hertan, Hilary MD, FACG1 Multi Segmental Asymptomatic Duplication of Colon: A Case Report, American Journal of Gastroenterology: October 2018 - Volume 113 Issue - p S947-S948

40. Kung-Chuan Cheng, Sheung-Fat Ko, Ko-Chao Lee. Case Reports Int J Colorectal Dis 2019 Nov; 34(11):1995-1998. Doi: 10.1007/s00384-019-034099. Epub 2019 Oct 23.

41. Shrestha S, Adhikari S. Colonic Duplication Cyst in an Adult Woman: A Case Report JNMA; Journal of the Nepal Medical Association. 2020 Nov; 58(231): 948-950. 
42. Li GB, Han JG, Wang ZJ, Zhai ZW, Tao Y. Successful management of tubular colonic duplication using a laparoscopic approach: A case report and review of the literature. World $\mathrm{J}$ Clin Cases. 2020 Aug 6; 8(15): 3291-3298. doi: 10. 12998/wjcc. v8.i15.3291. PMID: 32874984; PMCID: PMC7441256.

43. Reddy V, Eemaraka N, Jasmine YJ, Nayak SR. Intestinal duplication in an elderly-male presented as sigmoid volvulus. Formos J Surg 2021; 54:32-5 